\title{
Gastos com a saúde no Brasil: uma comparação com países de renda média ${ }^{1}$
}

\section{Vinicius Ratton Brandi ${ }^{2}$ Érica Quinaglia Silva ${ }^{3}$}

\begin{abstract}
Resumo: A saúde brasileira não se diferencia de muitas áreas de interesse público no Brasil, onde a realidade vivenciada pela população está muito distante da ampla cobertura registrada na lei. Este trabalho tem por objetivo avaliar a magnitude das despesas da sociedade brasileira na área da saúde, abrangendo tanto os gastos públicos como os gastos privados das famílias, a partir de uma comparação de dados agregados de países de renda média da América Latina e dos Brics. Os resultados indicam que os gastos na área da saúde no Brasil estão acima da média da amostra selecionada, com os gastos públicos ocupando uma posição intermediária, compatível com nosso nível de renda. Diante das restrições impostas pela condição econômica, é preciso intensificar o debate voltado à racionalização e priorização desses gastos.
\end{abstract}

Palavras-chave: Economia da saúde. Financiamento em saúde. Saúde pública.

\section{Health expenditures in Brazil: a comparison among middle-income countries}

\begin{abstract}
Brazilian health is not different from many areas of public interest in Brazil, where the reality experienced by the population is far from the broad coverage indicated in the law. This paper aims to assess the magnitude of Brazilian health expenditures based on a comparison of aggregate data from a sample of 12 middleincome countries of Latin America and Brics. Results indicate the total expenditure with health care in Brazil is higher than the sampled average, and that the public expenditures are consistent with our income level. Due to challenges imposed by economic conditions, it is necessary to intensify the debate focused on the definitions on prioritization of public expenditures.
\end{abstract}

Keywords: Health economics. Health funding. Public health.

1 As opiniões expressas neste trabalho são exclusivamente do(s) autor(es) e não refletem, necessariamente, a visão do Banco Central do Brasil.

2 Doutor em Economia pela Universidade de Brasília. Professor de Finanças. Analista do Banco Central do Brasil. E-mail: vinicius.brandi@gmail.com

3 Professora adjunta IV no Curso de Saúde Coletiva da Universidade de Brasília, professora permanente no Programa de Pós-Graduação em Antropologia da Universidade Federal do Pará e no Programa de Pós-Graduação em Ciências e Tecnologias em Saúde da Universidade de Brasília e pesquisadora do Instituto Nacional de Ciência e Tecnologia Brasil Plural. E-mail: equinaglia@hotmail.com 


\section{Classificação JEL: H51, I18}

\section{Introdução}

Ao criar o Sistema Único de Saúde (SUS), a Constituição de 1988 tornou universal o sistema público de saúde brasileiro, que anteriormente atendia apenas aos contribuintes da previdência social, por meio do Instituto Nacional de Assistência Médica da Previdência Social (Inamps). Esse foi o primeiro passo da nossa sociedade para tentar corrigir o que Deaton (2013) define como uma das maiores injustiças do mundo atual, a desigualdade no acesso à saúde. Nas palavras de Marques e Mendes (2005), deu-se uma "verdadeira inflexão no tratamento até então concedido pelo Estado".

Desde então, o financiamento dos gastos com saúde tem conquistado posição de destaque nos debates envolvendo aspectos de arrecadação tributária e de alocação orçamentária, com a finalidade última de garantir os pressupostos constitucionais que definem a saúde como um "direito de todos e dever do Estado" (BRASIL, 1988; PAIM et al., 2011). Após todos esses anos, o amplo reconhecimento é de que o SUS, como destaca Carvalho (2013), "mais faz do que deixa de fazer", porém seu subfinanciamento histórico tem se configurado como um impeditivo para sua universalização prática e melhorias de qualidade, como constatam Conceição, Cislaghi e Teixeira (2012).

O tema ganhou novo relevo, mais recentemente, no contexto das discussões que culminaram na promulgação da Emenda Constitucional no 95, de 15 de dezembro de 2016, que instituiu o Novo Regime Fiscal. De acordo com esse novo regramento, a partir de 2018, as aplicações mínimas do governo federal em ações e serviços públicos de saúde (ASPS) deixaram de ser fixadas com base em receitas tributárias e passaram a ser determinadas pelos próximos 20 anos com base no limite mínimo definido para o ano imediatamente anterior, corrigido pelo Índice Nacional de Preços ao Consumidor Amplo (IPCA). Considerando-se que esse novo regime estabeleceu também um teto para as despesas primárias do governo federal com base nas despesas do ano anterior ajustadas pelo mesmo índice de preços, a ampliação dos gastos federais na área da saúde não mais ocorrerá automaticamente em função de expansão da arrecadação federal, dependendo exclusivamente da priorização e racionalização dos gastos públicos ao longo do processo orçamentário.

O debate anterior à aprovação da reforma envolveu grandes tensões, uma delas em relação ao nível dos gastos públicos em saúde. Enquanto parece haver consenso sobre a necessidade de maior eficiência na aplicação dos recursos, preocupações de cunho fiscal e social têm motivado a manifestação de vozes 
antagônicas em relação ao montante ideal desses gastos. A capacidade para a realização de gastos públicos em saúde de qualquer economia está condicionada à sua geração de renda. Como destacam Savedoff et al. (2012), além de políticas públicas voltadas à ampliação do acesso à saúde e à promoção da equidade no atendimento, o crescimento da renda média de um país é uma das características comuns dos países que avançam na direção da consolidação de sistemas de cobertura universal. Além disso, a própria Organização Mundial da Saúde (OMS) (2000) reconhece a importância da renda média no provimento dos serviços de saúde, evidenciada na relação positiva encontrada entre o desempenho desses serviços no mundo e o nível de renda dos países.

Nossa condição de país de renda média configura-se, portanto, como um limitador para a ampliação dos gastos públicos em saúde nos níveis dos países avançados? Quais são nossas potencialidades? O Brasil gasta muito ou pouco na área da saúde? Essas são algumas das questões presentes na pauta das autoridades brasileiras, que buscam maximizar os efeitos das políticas públicas sujeitas às restrições de ordem econômica impostas, entre outras.

Este trabalho tem por objetivo contribuir para essa discussão, a partir de uma comparação dos gastos agregados da sociedade brasileira na área da saúde com os de países da América Latina e dos Brics (grupo de países composto por Brasil, Rússia, Índia, China e África do Sul), com níveis de renda média próximos ao do Brasil. Trata-se de uma pesquisa exploratória, realizada com base em dados da OMS referentes ao ano de 2014, último período disponível, e em dados divulgados pelo Fundo Monetário Internacional (FMI) referentes ao ano de 2015.

O restante deste artigo está dividido da seguinte forma: a seção seguinte apresenta uma breve revisão das principais regras de financiamento público da saúde, instituídas a partir da Constituição de 1988; a terceira seção descreve a amostra e a base de dados utilizadas; a quarta seção promove uma resumida análise dos gastos agregados de saúde no Brasil; a quinta seção expõe a comparação entre os países da amostra; e, por fim, a última seção apresenta as considerações finais.

\section{Financiamento da saúde a partir da Constituição de 1988}

A Constituição Federal de 1988 estabeleceu o financiamento da saúde com base no orçamento da seguridade social, composto por recursos provenientes dos orçamentos da União, dos estados, do Distrito Federal, dos municípios e de contribuições sociais específicas. No Ato das Disposições Constitucionais Transitórias (ADCT), o art. 55 determinou que, até que a lei de diretrizes orçamentárias fosse aprovada, no mínimo $30 \%$ do orçamento da seguridade social, excluído o seguro-desemprego, seria destinado ao setor da saúde. O SUS foi 
regulamentado, posteriormente, por meio da Lei no 8.080 , de 19 de setembro de 1990, e da Lei ${ }^{\circ}$ 8.142, de 28 de dezembro de 1990.

Nos anos subsequentes, os gastos com saúde passaram a competir com as demais despesas da previdência e assistência social, que também integram a seguridade social. Em 1998, a Emenda Constitucional no 20, de 15 de dezembro, incluiu vedação constitucional da utilização dos recursos provenientes de determinadas contribuições sociais para a "realização de despesas distintas do pagamento de benefícios do regime geral de previdência social".

A concorrência se ampliou ainda em relação a outras necessidades do governo federal, por conta da possibilidade de desvinculação de receitas com direcionamento obrigatório, instituída em 1994 pelo Fundo Social de Emergência (FSE) e, a partir de 2000, com a denominação de Desvinculação de Receitas da União (DRU), instituída pela Emenda Constitucional $\mathrm{n}^{\circ} 27$, de 21 de março do mesmo ano. Atualmente, a Emenda Constitucional ${ }^{\circ}$ 93, de 8 de setembro de 2016, prorrogou a DRU até 2023, com ampliação do percentual de desvinculação de $20 \%$ para $30 \%$, e estabeleceu regra semelhante para as receitas dos estados, Distrito Federal e municípios, vigorando até o mesmo prazo.

Vale frisar, no entanto, que, entre 1997 e 2007, a área da saúde recebeu reforço de financiamento proveniente $\mathrm{da}$ arrecadação da Contribuição Provisória sobre a Movimentação Financeira (CPMF), que, ao longo de sua vigência, ampliou seus campos de direcionamento de recursos abarcando a previdência social e o Fundo de Combate e Erradicação da Pobreza.

No ano 2000, a Emenda Constitucional n ${ }^{\circ} 29$, de 13 de setembro, representou grande avanço a favor da estabilidade e da ampliação dos benefícios proporcionados pelo SUS (DAIN, 2007). Com sua edição, estabeleceu-se um limite mínimo para as despesas da União com a saúde, equivalente ao montante empenhado no ano anterior, acrescido da variação do percentual do Produto Interno Bruto (PIB) nominal. Com isso, o legislador definia a aplicação mínima do orçamento federal para a área, sem explicitar pormenores a respeito de suas fontes de financiamento, permanecendo a saúde vinculada ao orçamento da seguridade social. Para os estados e municípios, os patamares mínimos foram definidos com base na aplicação de um fator equivalente a $7 \%$ sobre as receitas tributárias e transferências recebidas de cada ente federativo, percentual que deveria ser ampliado para $12 \%$ e $15 \%$, respectivamente, até o ano de 2004. Posteriormente, por meio da Resolução $n^{\circ} 322$, de 8 de maio de 2003, o Conselho Nacional de Saúde (CNS) estabeleceu as diretrizes relativas a esses percentuais mínimos ao longo do período de transição, entre os anos 2000 e $2004 .^{4}$

Após quase uma década de tramitação no Congresso Nacional, em 13 de janeiro de 2012, foi promulgada a Lei Complementar $\mathrm{n}^{\circ} 141$, responsável pela

4 Vide Campelli e Calvo (2007). 
definição das despesas com ações e serviços públicos de saúde que deveriam ser consideradas para fins de apuração dos patamares mínimos constitucionais. Foram consideradas aquelas concernentes à promoção, proteção e recuperação da saúde que atendessem, simultaneamente, aos princípios estatuídos no art. $7^{\circ}$ da Lei ${ }^{\circ} 8.080$, de 1990, e às diretrizes que preservassem a aplicação de recursos em ações de responsabilidade específica do setor da saúde, voltadas à promoção do acesso universal, igualitário e gratuito.

Dessa maneira, ainda que determinado tipo de despesa se enquadre nas atribuições amplas do SUS, definidas nos termos da Constituição Federal de 1988 e da Lei $n^{\circ} 8.080$, de 1990, isso não é suficiente para que seja computado como aplicação das despesas mínimas obrigatórias estabelecidas em nossa própria Carta Maior. É nesse sentido que o art. $4^{\circ}$ da Lei Complementar $n^{\circ} 141$, de 2012, exclui desse conjunto as despesas decorrentes dos pagamentos de aposentadorias e pensões, da assistência à saúde que não atenda ao princípio de acesso universal, da merenda escolar e outros programas de alimentação, entre outras.

Poucos anos depois, em consequência da edição da Emenda Constitucional $n^{\circ}$ 86, em 17 de março de 2015, os valores mínimos das despesas da União em ações na área da saúde passaram a ser definidos com base em sua arrecadação, harmonizando o critério para a definição desses patamares mínimos em relação aos demais entes federativos. No caso da União, esse mínimo foi fixado inicialmente em $13,2 \%$ de suas receitas correntes líquidas (RCL), convergindo gradualmente para 15\% em 2020, conforme o art. $2^{\circ}$ dessa Emenda Constitucional. ${ }^{5}$

Com a instituição do Novo Regime Fiscal, introduzido pela Emenda Constitucional $\mathrm{n}^{\circ}$ 95, de 2016, os gastos mínimos da União com saúde permaneceram definidos conforme a metodologia anterior em 2017, tendo como referência a receita corrente líquida, porém com percentual elevado para $15 \%{ }^{6}$, o que ocorreria somente em 2020, de acordo com a regra anteriormente vigente. No entanto, para os 19 anos subsequentes, o piso de gastos será definido com base no patamar mínimo do ano anterior e corrigido pelo IPCA. É importante destacar, a propósito, que o novo regime não se aplica aos gastos dos estados e municípios, nem às transferências constitucionais da União, as quais financiam as despesas com saúde em âmbito regional em última instância.

Comparativamente ao modelo instituído no ano 2000 pela Emenda Constitucional $\mathrm{n}^{\mathrm{o}} 29$, as despesas mínimas voltam a ser definidas, tendo como referências os valores das despesas dos anos anteriores. A diferença é que a referência atual se dá pelo patamar mínimo do ano anterior, e não mais pelas despesas

5 Vide Funcia (2015).

6 Brasil. Constituição da República Federativa do Brasil de 1988, Ato das Disposições Conjuntas Transitórias, art. 110, inciso I. 
empenhadas; já a correção da medida de referência do ano anterior se dá apenas pela inflação, não proporcionando ganhos reais adicionais provenientes dos ajustes em função da variação do PIB.

\section{Amostra e base de dados}

A partir de revisão de trabalhos empíricos, Gerdtham e Jönsson (2000) identificam o nível de renda como um dos principais fatores que explicam a variação dos gastos na área da saúde entre os diferentes países. Assim, na tentativa de controlar os efeitos decorrentes da diferença de renda nesta análise, foram selecionados os países da América Latina e dos Brics, considerados pelo FMI como economias emergentes ou de renda média, compreendendo uma amostra de 12 países: Argentina, Brasil, Chile, China, Colômbia, Equador, México, Peru, Rússia, África do Sul, Uruguai e Venezuela.

Por apresentarem níveis de renda aproximados, esses países são comumente utilizados na literatura para diversos tipos de comparação internacional de variáveis influenciadas pela riqueza por eles gerada ${ }^{7}$. Deve-se registrar, no entanto, que as conclusões extraídas a partir desse tipo de comparação devem ser consideradas com certa cautela, uma vez que não são observados na análise outros fatores relevantes relacionados às condições políticas, demográficas, geográficas e climáticas, por exemplo.

A Figura 1 apresenta estatísticas macroeconômicas básicas referentes ao PIB, ao nível de endividamento público e à carga tributária dos países da amostra, em ordem crescente. Essas informações são úteis para identificar a geração de riqueza individual média de cada economia, bem como as fontes de captação do governo para financiar seus gastos. As informações referem-se ao ano de 2015 e foram obtidas na base de dados de abril de 2017 do World Economic Outlook, disponibilizada pelo FMI.

7 Veja Ribeiro (2008) como exemplo de estudo de comparação de gastos públicos. 
Figura 1 - Estatísticas Macroeconômicas Básicas. Ano: 2015

\begin{tabular}{lr}
\hline \multicolumn{1}{c}{ Países } & $\begin{array}{c}\text { PIB per capita } \\
\text { (PPP - Internat. US\$) }\end{array}$ \\
\hline \hline Equador & $11.379,35$ \\
Peru & $12.389,08$ \\
África do Sul & $13.229,62$ \\
Colômbia & $13.833,29$ \\
China & $14.328,14$ \\
Brasil & $15.729,29$ \\
Venezuela & $16.784,14$ \\
México & $18.463,19$ \\
Argentina & $20.472,47$ \\
Uruguai & $21.026,23$ \\
Chile & $23.681,79$ \\
Rússia & $26.207,82$ \\
\hline
\end{tabular}

\begin{tabular}{lc}
\hline \multicolumn{1}{c}{ Países } & $\begin{array}{c}\text { Dívida Bruta do } \\
\text { Governo Geral (\%PIB) }\end{array}$ \\
\hline \hline Rússia & $15,9 \%$ \\
Chile & $17,4 \%$ \\
Equador & $22,6 \%$ \\
Peru & $24,0 \%$ \\
Venezuela & $32,1 \%$ \\
China & $42,6 \%$ \\
África do Sul & $49,8 \%$ \\
Colômbia & $50,7 \%$ \\
Argentina & $52,0 \%$ \\
México & $53,7 \%$ \\
Uruguai & $64,3 \%$ \\
Brasil & $72,5 \%$ \\
\hline
\end{tabular}

\begin{tabular}{lc}
\hline \multicolumn{1}{c}{ Países } & $\begin{array}{c}\text { Carga Tributária } \\
\text { (\%PIB) }\end{array}$ \\
\hline \hline Venezuela & $19,2 \%$ \\
Peru & $20,0 \%$ \\
Chile & $23,0 \%$ \\
México & $23,1 \%$ \\
Colômbia & $26,4 \%$ \\
China & $28,5 \%$ \\
Uruguai & $28,7 \%$ \\
África do Sul & $29,6 \%$ \\
Brasil & $31,2 \%$ \\
Rússia & $31,8 \%$ \\
Equador & $33,5 \%$ \\
Argentina & $33,9 \%$ \\
\hline
\end{tabular}

Fonte: FMI - World Economic Outlook (Abril de 2017). PIB per capita: GDP per capita based on purchasing power parity (PPP).

Dívida Bruta do Governo Geral: General Government Gross Debt. Carga Tributária: General Government Revenue.

Os resultados indicam características conhecidas da economia brasileira: um país com uma renda per capita intermediária, comparativamente aos países de renda média da amostra, e com níveis de endividamento bruto e de carga tributária superiores. O Brasil é o país com o $7^{\circ}$ maior PIB per capita da amostra, medida que representa o valor adicionado por todos os bens e serviços produzidos pela economia, dividido pelo tamanho da população. Como medida de geração de renda individual, o PIB per capita impõe limites à capacidade de cada país em disponibilizar bens e serviços voltados para o bem-estar da sociedade em relação aos gastos na área da saúde, como lembram Dmytraczenko e Almeida (2016). Para melhor referência, destaque-se que o PIB per capita da região da América Latina e do Caribe é equivalente a US\$15.510,1, ao passo que o das economias avançadas é equivalente a US $\$ 46.240,6$.

Os dados referentes à dívida bruta do governo geral e à carga tributária, por sua vez, indicam como os governos utilizam esses instrumentos para financiar suas atividades. Valores mais elevados sugerem uma maior intervenção do Estado na economia. Uma diferença entre elas é que, enquanto a carga tributária compromete a capacidade de gastos individuais da geração corrente, o endividamento tem por objetivo antecipar o recebimento de recursos que serão custeados pelas gerações futuras por meio de amortizações de dívida e de pagamento de juros.

Os demais valores das variáveis apresentadas nas seções seguintes, referentes inclusive aos gastos na área da saúde, foram obtidos na base de dados da OMS, presente no site do Banco Mundial, sendo 2014 o último ano disponível. Os valores 
são apresentados com base na paridade do poder de compra do dólar dos Estados Unidos, a preços de 2011, conforme metodologia definida pelo Banco Mundial para permitir melhor comparação entre os diferentes países. No caso do Brasil, a taxa de câmbio R\$/US\$ utilizada é equivalente a 1,85.

\section{Gastos com a saúde no Brasil}

No Brasil, os gastos totais na área da saúde, públicos e privados, têm apresentado crescimento consistente nas últimas décadas, conforme se observa na Figura 2. Segundo Machado, de Lima e de Andrade (2014), esse comportamento se deve tanto ao crescimento econômico, representado pelo aumento no PIB per capita ao longo do período de 1995 a 2014, como também a uma maior participação dos gastos com a saúde na distribuição da riqueza nacional.

Em 1995, os gastos com a saúde totalizaram 6,5\% do PIB, valor que cresceu e permaneceu estável em torno de $8,3 \%$ do PIB a partir de 2005. Ainda assim, os gastos nominais individuais se mantiveram crescentes em decorrência do crescimento da economia brasileira, saltando de US\$524, em 1995, para U\$1.318 ao ano por habitante, em 2014. Essa tendência dos dados nominais não se altera substancialmente quando se comparam os gastos discriminados entre os setores público e privado, acompanhando o crescimento da renda nacional e, também, como consequência direta das alterações legais que estabeleceram gastos mínimos cada vez mais significativos. Em comparação com o PIB, no entanto, observa-se que os gastos privados se reduzem de forma acentuada a partir de 2005, indicando que esses gastos com a saúde não acompanharam o crescimento do PIB mais acentuado, observado a partir desse ano. Já os gastos públicos demonstraram um crescimento relativamente constante acima do PIB entre 2000 e 2010.

A Figura 3(a) mostra que os gastos públicos na área da saúde têm sido inferiores aos gastos privados no decorrer dos últimos anos, representando valores anuais entre $40 \%$ e $47 \%$ dos gastos totais. De acordo com Barros e Piola (2016), essa menor participação do gasto público é um caso único entre países que dispõem de um sistema universal de saúde. E essa pequena diferença percentual torna-se bem discrepante quando consideramos que a quantidade de pessoas atendidas pelo serviço público de saúde é bastante superior aos beneficiários cobertos por planos de saúde privados. 
Figura 2 - Gasto anual na área da saúde

(a) PIB per capita

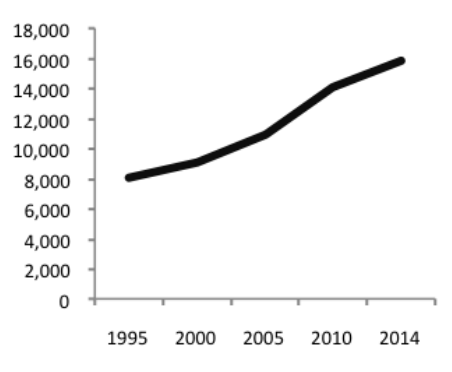

(b) Gasto em saúde per capita

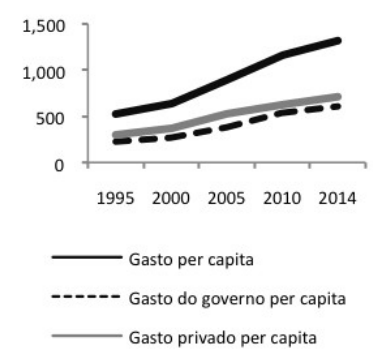

(c) Gasto em saúde $\%$ PIB

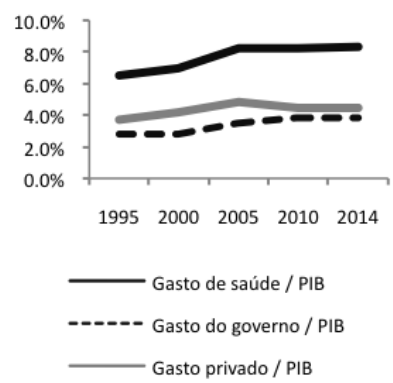

Fonte: Banco Mundial/Organização Mundial da Saúde.

Figura 3 - Gastos anuais relativos

(a) Percentual dos gastos públicos

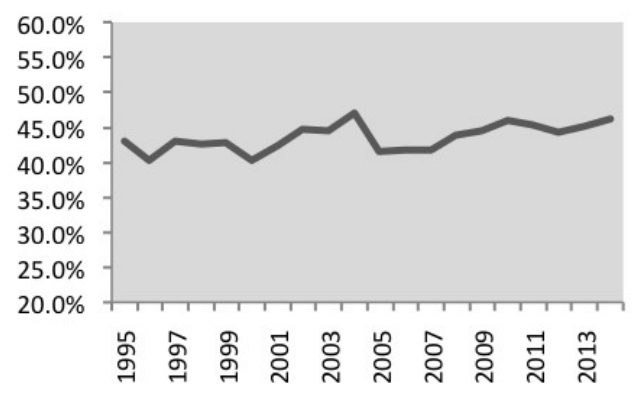

Fonte: Banco Mundial/Organização Mundial da Saúde. (b) Composição dos gastos privados

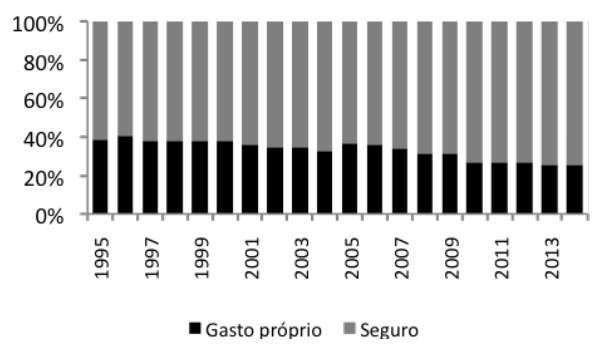

Fonte: Banco Mundial/Organização Mundial da Saúde.

Gasto próprio: out-of-pocket expenditures.

De acordo com dados da Agência Nacional de Saúde Suplementar (ANS), a taxa de cobertura por planos de saúde no Brasil tem sido equivalente a aproximadamente $25 \%$ da população total nos anos mais recentes, com taxas bastante inferiores a essa nas regiões Norte e Nordeste. Supondo que essa mesma parcela é beneficiada apenas pelos gastos privados e a outra parcela apenas pelos gastos públicos, tem-se um gasto per capita privado equivalente a US\$2.845 e público de US\$ 809,2. Em um estudo publicado em 2008, Albuquerque et al. (2008) encontram proporções semelhantes, evidenciando a enorme desigualdade de acesso à saúde e a iniquidade nos serviços dessa área, como também verificado por Neri e Soares (2002). 
Com relação aos gastos privados, a Figura 3(b) revela uma participação cada vez menor de despesas de tratamento pagas diretamente pelos pacientes, em que o percentual dos gastos privados custeados com recursos próprios das famílias caiu de $39 \%$, em 1995, para 25\%, em 2014. Isso se deveu em grande parte à maior formalização da economia e ao aumento de renda da população, permitindo o acesso de um número maior de famílias aos planos de saúde suplementares, que também são computados como gastos privados.

\section{Comparação internacional}

Os esforços para a ampliação de gastos na área da saúde podem ser endereçados de diferentes maneiras. Em uma perspectiva macroeconômica, a adoção de políticas que favoreçam o crescimento e a maior capacidade de geração de riqueza da economia é responsável por proporcionar uma quantidade maior de bens e serviços a serem distribuídos à população. Ainda, por meio de aprimoramentos específicos na área de planejamento e de gestão, é possível prover serviços em maior quantidade e qualidade sem um correspondente acréscimo orçamentário.

No campo das Finanças Públicas, são discutidas estratégias de tributação e de endividamento que possam influenciar a capacidade do Estado de realizar despesas primárias ao longo de diferentes períodos de tempo. $\mathrm{O}$ aspecto intergeracional é uma característica inerente a essas questões na medida em que o aumento de gastos correntes do governo terá efeitos sobre o potencial de benefícios estatais em momentos posteriores. Essa relação se impõe não somente pelas restrições financeiras, mas também por conta dos efeitos das decisões fiscais sobre o crescimento econômico.

A literatura econômica é rica em estudos que relacionam o crescimento econômico a variáveis macroeconômicas, como o nível de endividamento e a carga tributária. Reinhart e Rogoff (2010) apresentam um estudo de destaque contendo evidências sobre o efeito negativo do endividamento público nas taxas de crescimento. Alesina e Ardagna (2010) documentam os diferentes efeitos nas taxas de crescimento econômico decorrentes de políticas de estímulo fiscal, implementadas por meio da redução de impostos ou pelo aumento de gastos públicos. $\mathrm{Na}$ comparação entre os países da amostra, ilustrada na Figura 1, o Brasil se destaca por ser um país com elevados níveis de endividamento e de carga tributária.

Por fim, há uma questão central às discussões orçamentárias em todas as áreas que demandam intervenção governamental, como saúde, educação, assistência social, habitação, desenvolvimento econômico, previdência, entre outras, que consiste na decisão sobre a priorização dos gastos públicos, favorecendo áreas específicas, consideradas de maior importância pelo setor público. 
É importante salientar, antes de se avançar na análise, que a condição de boa saúde não se obtém unicamente pelo direcionamento de recursos públicos à recuperação e ao tratamento das pessoas doentes. A própria OMS amplia, desde a sua constituição em 1948, a definição de saúde, que passa a ser considerada como um estado de completo bem-estar físico, mental e social, e não apenas a ausência de enfermidade (SCLIAR, 2007). Essa definição traz como pano de fundo a ideia de que afetam a saúde os seus determinantes sociais, ou seja, fatores econômicos, culturais, étnicos/raciais, psicológicos e comportamentais.

Adicionalmente, é importante destacar que a saúde é apenas uma das diversas dimensões que caracterizam o bem-estar individual, que inclui, ainda, outros aspectos relacionados à educação, ao consumo, ao transporte, à segurança, etc. Deaton (2013) ressalta que renda e saúde são dois dos componentes mais importantes do bem-estar e, considerando que os tratamentos de saúde são cada vez mais caros e eficientes, as decisões de políticas públicas devem observar os trade-offs existentes na escolha sobre maiores ou menores gastos na área da saúde, numa abordagem holística na busca pela maximização do bem-estar social.

Enquanto os países ricos podem oferecer serviços de saúde a níveis satisfatórios sem comprometer significativamente os gastos com outras atividades, os países mais pobres se deparam com dificuldades muito maiores para conciliar a distribuição dos gastos públicos sempre bastante escassos com as demandas da sociedade. Nesse sentido, as reflexões sobre os gastos médios aqui apresentados devem ser colocadas com parcimônia, com a consciência de que há bastante desigualdade na distribuição desses gastos e de que, na realidade dos países de renda média, os gastos em saúde possuem um custo de oportunidade elevado em termos de bem-estar.

A Figura 4(a) apresenta os gastos anuais em saúde, variando desde US\$ 656, no caso do Peru, até o máximo de US\$1.836, no da Rússia. O Brasil é o país com o $4^{\circ}$ maior gasto, representado tanto em termos absolutos, em gastos per capita, como relativos, na proporção do PIB. Os gastos per capita tendem a indicar não somente o interesse da sociedade em despender recursos em determinada área, mas também as restrições impostas pelo tamanho da renda de cada país, como salientado por OckéReis (2008). A correlação de postos de Spearman entre PIB per capita e gastos de saúde per capita na amostra equivale a 0,70, indicando uma alta relação positiva entre as ordens dos países em sequências crescentes de ambas as variáveis.

Observa-se que todos os países com gastos per capita maiores que o Brasil (Rússia, Uruguai e Chile) apresentam rendas médias no mínimo 35\% maiores e, portanto, possuem mais renda para direcionar para as áreas de seu interesse. Ainda, os gastos brasileiros em saúde precisariam aumentar cerca de 170\% para nos igualarmos aos gastos nos países da União Europeia e 250\% em comparação aos países da 
Organização para a Cooperação e Desenvolvimento Econômico (OCDE), composta por 34 países de renda média alta.

Apesar de ser o país com o $7^{\circ}$ maior PIB per capita, a $4^{a}$ colocação no ranking dos gastos com saúde per capita revela, de certa forma, a inclinação da sociedade brasileira em priorizar mais a área da saúde, nesta comparação internacional, que se consolidou a partir da criação do SUS e das Emendas Constitucionais antepostas, que promoveram uma ampliação dos gastos mínimos nessa área. $\mathrm{Na}$ avaliação dos gastos relativos ao tamanho do PIB desses países, apenas o Uruguai permanece à frente do Brasil, com a Rússia caindo para a $7^{\mathrm{a}}$ posição. Isso pode indicar, de alguma maneira, que a sociedade, ao atingir certo patamar de condição de saúde, busca priorizar os gastos em outras áreas que também contribuam para seu bem-estar, na hipótese defendida por Deaton (2013).

Outro fator relevante para a comparação dos gastos em saúde está relacionado ao modelo de proteção social adotado em cada jurisdição. Como uma das metas no conjunto de ações voltadas para o desenvolvimento sustentável, os países membros das Nações Unidas concordaram em direcionar esforços para implementar sistemas universais de saúde até o ano de $2030^{8}$. Segundo estudo publicado em 20109, no entanto, dos países da amostra aqui analisada, apenas Argentina, Chile e Venezuela, além do Brasil, possuíam sistemas de cobertura universal efetivos.

As diferenças entre os gastos públicos e privados podem ser analisadas a partir das Figuras 4 (c), (d), (e) e (f). Enquanto o Brasil é o $3^{\circ}$ país com a maior parcela de gastos privados, situa-se na $6^{a}$ posição na classificação de gastos públicos. Comparativamente aos países da amostra, os gastos públicos na área da saúde se encontram em patamar compatível com sua posição intermediária em termos de renda per capita, não podendo ser considerados nem baixos nem elevados. A correlação de postos de Spearman entre o PIB per capita e os gastos de saúde públicos e privados per capita na amostra é equivalente a 0,69 e 0,52, respectivamente, apontando uma menor relação da medida de renda com os gastos privados.

8 Universal health coverage. http://www.who.int/mediacentre/factsheets/fs395/en/

9 Stuckler et al. (2010). 
Figura 4 - Gastos públicos e privados em saúde (2014)

(a) Gasto anual per capita

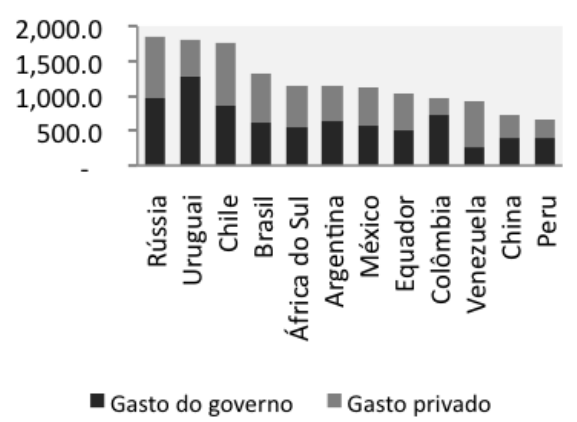

(c) Gasto público per capita

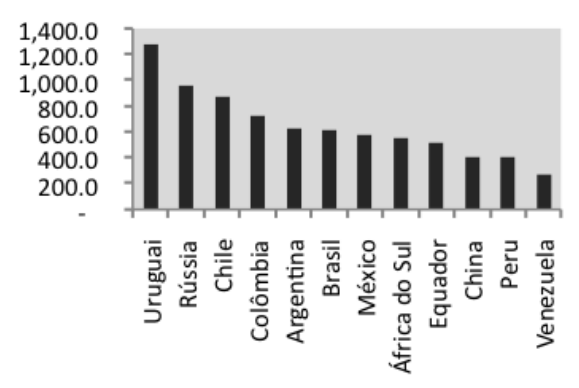

(e) Gasto privado per capita

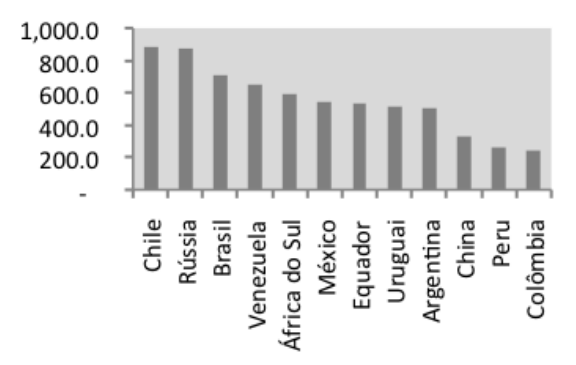

(b) Gasto anual \% PIB

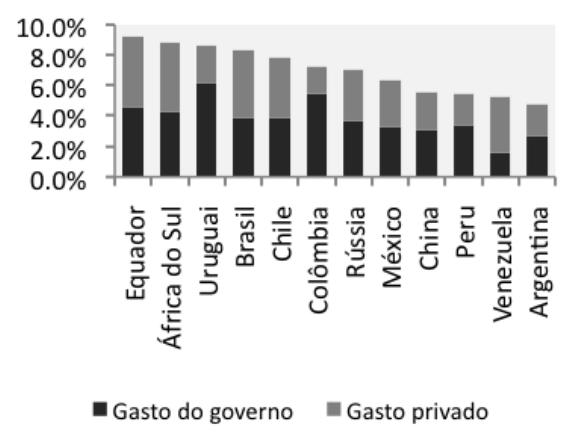

(d) Gasto público - \%PIB

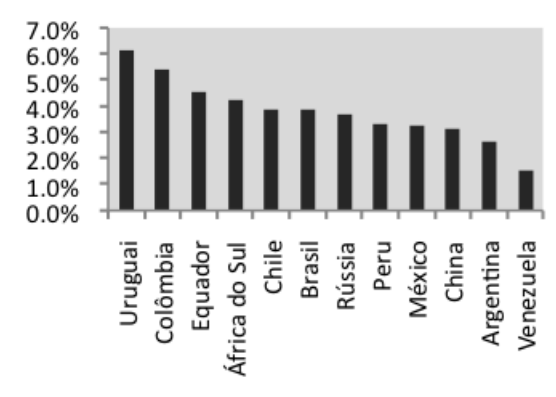

(f) Gasto privado - \%PIB

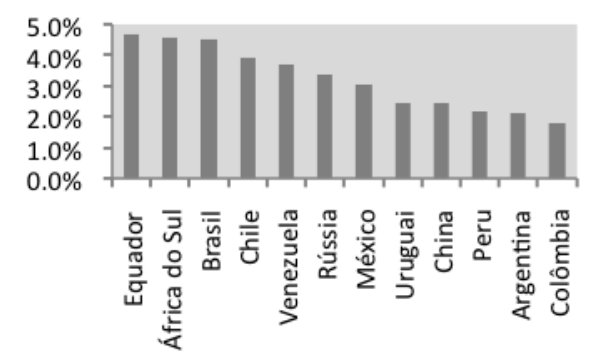

Fonte: Banco Mundial/Organização Mundial da Saúde.

Esse resultado pode ser explicado, em parte, pela desigualdade existente em nossa sociedade. De um lado, o Brasil possui uma parcela da população com condição de renda suficiente para custear serviços suplementares. Do outro, a economia brasileira ainda não alcançou o grau de desenvolvimento necessário para 
oferecer a mesma qualidade de serviços a toda a população. Dos países com gastos públicos per capita na área da saúde superiores aos do Brasil (Uruguai, Rússia, Chile, Colômbia e Argentina), todos possuem renda per capita superior. Essa relação se altera na comparação dos gastos proporcionais ao PIB, em que três países com renda média inferior à nossa (Colômbia, Equador e África do Sul) apresentam números superiores ao brasileiro.

As diferenças entre gastos públicos e privados podem ser observadas sob várias perspectivas. Deve-se ter em mente que os gastos do governo não são a única forma de financiar os serviços de saúde. Em países com baixa desigualdade, por exemplo, o governo poderia ampliar os gastos da sociedade com saúde por meio da redução da tributação, permitindo que parcelas maiores da renda das famílias pudessem ser disponibilizadas para seus gastos individuais. No outro oposto, o governo poderia manter níveis mais elevados de tributação para oferecer um serviço padronizado para toda a população. No caso de países com maior desigualdade socioeconômica, como é mais comum entre os países de renda média, a definição sobre os gastos públicos tende a assumir caráter distributivo, uma vez que tais serviços são financiados pela parcela mais rica da população e beneficiam os estratos de renda mais baixa, principalmente em um regime tributário progressivo.

A Figura 5(a) apresenta a proporção dos gastos públicos sobre o total de gastos em saúde em três anos ao longo das últimas duas décadas. Em geral, não se observa uma tendência única em relação a essa medida. Há países, como Colômbia, Uruguai, Peru, México e África do Sul, que têm demonstrado crescimento relativo dos gastos públicos, e outros, como Argentina e Rússia, com tendências decrescentes. $\mathrm{Na}$ comparação, o Brasil ocupa a penúltima colocação, à frente apenas da Venezuela, sendo o único país com sistema universal previsto na legislação com gastos públicos inferiores aos privados, conforme mencionado anteriormente.

Figura 5 - Percentual dos gastos públicos em saúde

(a) Gastos públicos / Total

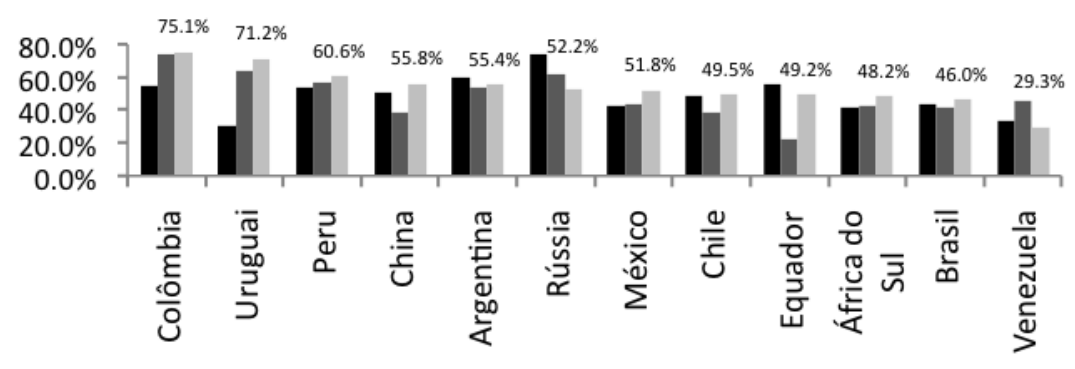

" $1995 \quad 2005=2014$ 
(b) Gastos de saúde como proporção dos gastos públicos totais

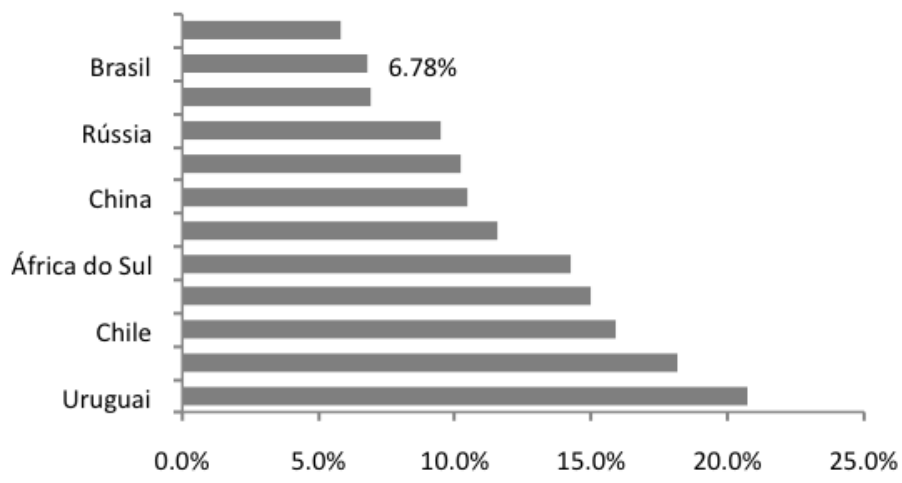

Fonte: Banco Mundial/Organização Mundial da Saúde.

Obs.: Rótulo no gráfico 5(a) indica valor de 2014.

A Figura 5(b) apresenta os gastos públicos na área da saúde como proporção dos gastos totais do governo, em todas as suas esferas. Em oito países da amostra aqui analisada, o percentual dos gastos com a saúde em relação aos gastos públicos totais é superior ao percentual brasileiro, alguns com valores bem acima, chegando até $20,8 \%$, como é o caso do Chile. Isso revela como os gastos na área da saúde desses países são priorizados na distribuição dos recursos provenientes de seus esforços de arrecadação. Os resultados podem surgir da discricionariedade do legislador na construção das peças orçamentárias a cada ano ou, como no caso brasileiro, da consequência de imposições presentes em regras constitucionais que estabelecem gastos obrigatórios em áreas concorrentes, como no caso da previdência social.

\section{Considerações finais}

A saúde brasileira não se diferencia de muitas áreas de interesse público no Brasil, onde a realidade vivenciada pela população está muito distante da ampla cobertura registrada na letra da lei. $\mathrm{Na}$ comparação aqui realizada foi possível observar que os gastos na área da saúde no Brasil estão acima da média dos países de renda comparável selecionados. Com relação aos gastos públicos, observa-se que a posição intermediária ocupada pelo Brasil é compatível com seu nível intermediário de renda na amostra. A magnitude relativa dos gastos privados, por sua vez, sugere uma maior desigualdade de acesso à saúde, em termos comparativos. Ainda, observa-se que a maioria dos países da amostra possui 
participação relativa da saúde nos gastos totais do governo maior do que a do Brasil, refletindo uma característica da economia brasileira nesses últimos anos, em que parte substancial dos recursos públicos é direcionada para o pagamento de serviços da dívida pública e de gastos previdenciários.

É preciso destacar, assim, que a condição de subfinanciamento do sistema público de saúde brasileiro se impõe como restrição à plena garantia do direito à saúde. Essa condição se torna ainda mais desafiadora tendo em conta a aprovação do Novo Regime Fiscal, instituído nos termos da Emenda Constitucional no 95, de 2016, que definiu um limite superior para as despesas primárias do governo federal.

Diante desse quadro, torna-se imperativo aprofundar a discussão sobre a eficiência e o modelo de distribuição dos gastos públicos, sem efeitos secundários que comprometam as contas públicas. No âmbito da saúde, deve-se considerar, ainda, a priorização dos gastos entre suas diferentes categorias ${ }^{10}$. Trata-se, destarte, do desafio de prover o máximo de justiça e de bem-estar em decorrência da atuação do poder público, consciente de que existe uma restrição de ordem econômica relacionada ao nível de renda do país.

\section{Referências}

ALBUQUERQUE C, PIOVESAN MF, SANTOS IS, MARTINS ACM, FONSECA AL, SASSON D, SIMÕES KA. A situação atual do mercado da saúde suplementar no Brasil e apontamentos para o futuro. Ciência e Saúde Coletiva, 2008; 13(5): 1421-1430. DOI: https://doi.org/10.1590/S1413-81232008000500008

ALESINA A, ARDAGNA S. Large changes in fiscal policy: taxes versus spending. In: Brown JR, editor. Tax Policy and the Economy, Vol. 24, Univ. of Chicago Press; 2010. p. 35-68. DOI: https://doi.org/10.1086/649828

BARROS M.E.D, PIOLA S.F. O financiamento dos serviços de saúde no Brasil. In: Marques RM, Piola SF, Roa AC. Sistema de saúde no Brasil: organização e financiamento. Rio de Janeiro: ABrES; Brasília: Ministério da Saúde; 2016. p. 101-138.

BRASIL. Constituição da República Federativa do Brasil de 1988. Diário Oficial da União, 1988.

CAMPELli M.G.R, CALVO M.C.M. O cumprimento da Emenda Constitucional no. 29 no Brasil. Cadernos de Saúde Pública, 2007; 23(7): 1613-1623. DOI: https://doi.org/10.1590/S0102-311X2007000700012

10 OCDE. Relatórios econômicos da OCDE: Brasil. 2015. 
CARVAlHO G. A saúde pública no Brasil. Estudos Avançados. 2013; 27(78): 7-26. DOI: https://doi.org/10.1590/S0103-40142013000200002

CONCEIÇÃO T.S, CISLAGHI J.F, TEIXEIRA S.O. O financiamento da saúde no Brasil: Principais dilemas. Temporalis, 2012; 12(23): 97-124.

DAIN S. Os vários mundos do financiamento da saúde no Brasil: uma tentativa de integração. Ciência e Saúde Coletiva, 2007; 12 (Suppl.): 1851-1864. DOI: https://doi.org/10.1590/S1413-81232007000700008

DEATON A. The great escape: Health, wealth, and the origins of inequality. Princeton: University Press; 2013. DOI: https://doi.org/10.2307/j.ctt3fgxbm

DMYTRACZENKO T, ALMEIDA G. Rumo a uma cobertura universal de saúde e equidade na América Latina e no Caribe: Evidência de países selecionados. Grupo Banco Mundial. 2016. DOI: https://doi.org/10.1596/978-1-4648-0920-0

FUNCIA, F. Implicações da Emenda Constitucional n. 86/2015 para o processo de financiamento do Sistema Único de Saúde. Revista Consensus, 2015; Edição 15: 36-40.

GERDTHAM U-G, JÖNSSON B. International comparisons of health expenditure: Theory, data and econometric Analysis. In: Handbook of Health Economics; 2000. p. 11-53. DOI: https://doi.org/10.1016/S1574-0064(00)80160-2

IBANEZZ N, VECINA NETO G. Modelos de gestão e o SUS. Ciência e Saúde Coletiva, 2007; 12(Suppl.): 1831-1840. DOI: https://doi.org/10.1590/S141381232007000700006

MACHADO C.V, DE LIMA L.D, DE ANDRADE C.L.T. Federal funding of health policy in Brazil: Trends and challenges. Ciência e Saúde Coletiva, 2014; 30(1): 187-200. DOI: https://doi.org/10.1590/0102-311X00144012

MARQUES R.M, MENDES Á. Os dilemas do financiamento do SUS no interior da seguridade social. Economia e Sociedade, 2005; 14(1-24): 159-175. DOI: https://doi.org/10.1590/S0104-12902005000200005

NERI M, SOARES W. Desigualdade social e saúde no Brasil. Ciência e Saúde Coletiva, 2002; 18: 77-87. DOI: https://doi.org/10.1590/S0102-311X2002000700009 
OCDE. Relatórios econômicos da OCDE: Brasil. 2015.

OCKÉ-REIS C.O. Os problemas de gestão do SUS decorrem também da crise crônica de financiamento? Trabalho, Educação e Saúde, 2008; 6 (3):613-622. DOI: https://doi.org/10.1590/S1981-77462008000300012

ORGANIZAÇÃO MUNDIAL DA SAÚDE. The World Health Report. Health systems: Improving performance. 2000.

PAIM J, TRAVASSOS C, ALMEIDA C, BAHIA L, MACINKO J. O sistema de saúde brasileiro: história, avanços e desafios. Lancet 2011; 11-31.

RIBEIRO M.B. Desempenho e eficiência do gasto público: Uma análise comparativa do Brasil em relação a um conjunto de países da América Latina. Rio de Janeiro: Ipea; 2008.

REINHART C.M, ROGOFF K.S. Growth in a Time of Debt. American Economic Review, 2010; 100 (2): 573-578. DOI: https://doi.org/10.1257/aer.100.2.573

SAVEDOFF W.D, DE FERRANTI D, SMITH A.L, FAN V. Political and economic aspects of the transition to universal health coverage. Lancet 2012; 380 (9845): 924932. DOI: https://doi.org/10.1016/S0140-6736(12)61083-6

SCLIAR M. História do conceito de saúde. Physis: Revista de Saúde Coletiva, 2007; 17(1): 29-41. DOI: https://doi.org/10.1590/S0103-73312007000100003

STUCKLER D, FEIGL A.B, BASU S, MCKEE M. The political economy of universal health coverage. Background paper. First Global Symposium on Health Systems Research. 2010.

UNIVERSAL HEALTH COVERAGE. [2017 mai 20]. Disponível em http://www.who.int/mediacentre/factsheets/fs395/en/ .

Recebido em 10.11.17

Aprovado em 09.01.19 